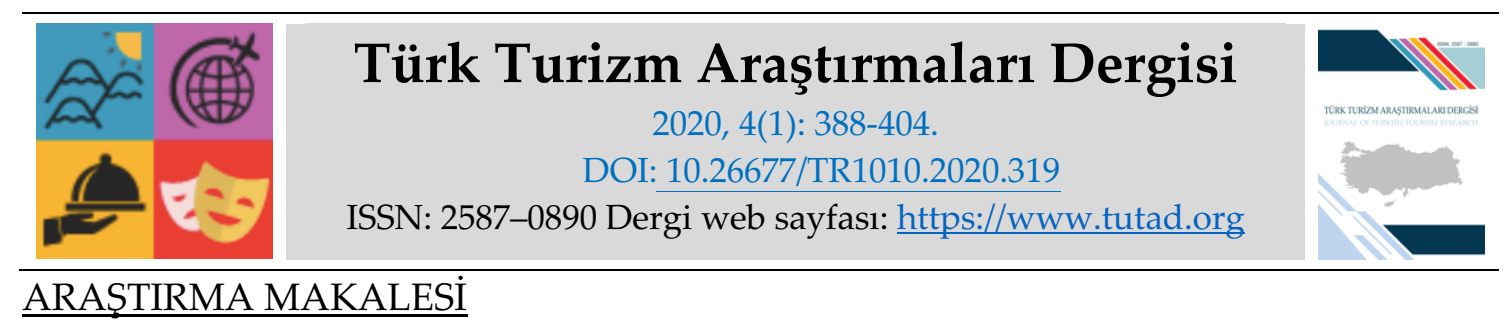

\title{
Engelli Turizmi Alanındaki Lisansüstü Tezlerin Bibliyometrik Analizi*
}

Doç. Dr. Emre Ozan AKSÖZ, Anadolu Üniversitesi, Turizm Fakültesi, Eskişehir, e-posta: ozana@anadolu.edu.tr ORCID: https://orcid.org/0000-0002-4109-8847

Öğr. Gör. Dr. Esin YÜCEL, Akdeniz Üniversitesi, Akdeniz Uygarlıkları Araştırma Enstitüsü, Antalya, e-posta: esinyucel@akdeniz.edu.tr ORCID: https://orcid.org/0000-0003-1371-8911

\section{Öz}

Bu çalışmada, engelli turizmi ile ilgili 1987-2019 yılları arasında yayımlanan lisansüstü tezlerin çeşitli parametreler çerçevesinde bibliyometrik özelliklerinin belirlenmesi amaçlanmıştır. Araştırmanın bir diğer amacı ise engelli turizmi konusunda alan yazının genel özelliklerini ortaya koyarak araştırmacılara kolaylık sağlamaktır. Bu amaçla Yükseköğretim Kurulu veri tabanında yer alan turizm alanındaki lisansüstï tezler "engelli turizm", "engelsiz turizm", "erişilebilir turizm", "ulaşılabilir turizm" ve "herkes için turizm" anahtar kelimeleri ile taranmıs, ve toplam 55 adet teze ulaşılmıştır. Ulaşılan tezler; yıllarına, türlerine (yüksek lisans/doktora), araştırma desenlerine, anahtar kelimelerine, yazım diline, yayımlandıkları enstitü ve anabilim dallarına göre incelenmiştir. Araştırma kapsamına dâhil edilen tezler, ilgili parametreler doğrultusunda istatistiki program aracılığıyla frekans analizine tabi tutulmuş, ve bibliyometrik analiz ile değerlendirilmiştir. Araştırma bulgularına göre yazılan tezlerin büyük çoğunluğu yüksek lisans tezleridir. Çoğunlukla sosyal bilimler enstitüleri çatısı altında 8 ayrı ana bilim dalında yazıldıkları tespit edilen tezlerde veri elde etme aracı olarak en çok anket tekniğinin kullanıldığı tespit edilmiştir.

* Bu çalışma, 26-28 Eylül 2019 tarihlerinde Mersin'de gerçekleştirilen 3. Uluslararası Turizmin Geleceği; İnovasyon, Girişimcilik ve Sürdürebilirlik Kongresi'nde sözlü bildiri olarak sunulmuştur.

Anahtar Kelimeler: Bibliyometri, Engelli Turizmi, Erişilebilirlik, Lisansüstü Tezler.

Makale Gönderme Tarihi: 23.10.2019

Makale Kabul Tarihi: 04.01.2020

\section{Önerilen Atıf:}

Aksöz, E. O. ve Yücel, E. (2020). Engelli Turizmi Alanındaki Lisansüstü Tezlerin Bibliyometrik Analizi, Türk Turizm Araştırmaları Dergisi, 4(1): 388-404.

(C) 2020 Türk Turizm Araştırmaları Dergisi. 


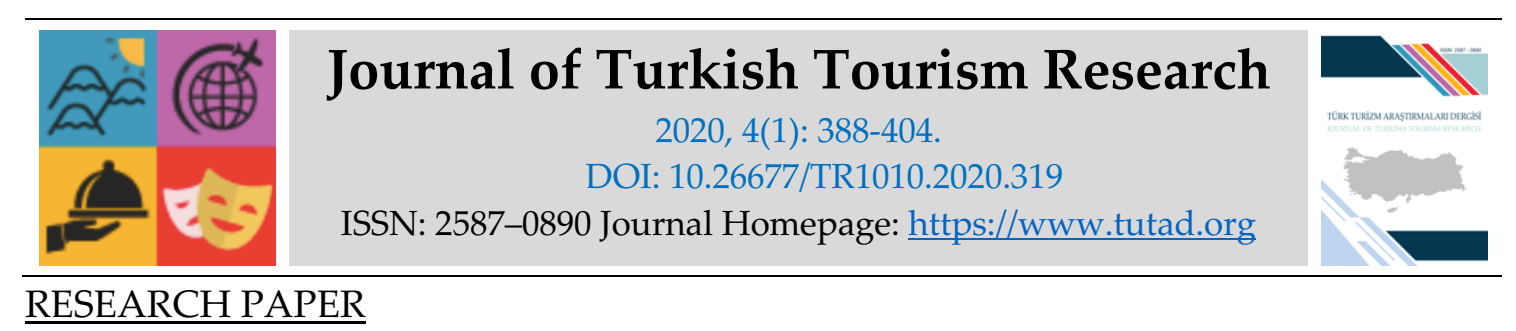

Bibliometric Analysis of Graduate Thesis in Disabled Tourism

Doç. Dr. Emre Ozan AKSÖZ, Anadolu University, Faculty of Tourism, Eskişehir, e-mail: ozana@anadolu.edu.tr

ORCID: https://orcid.org/0000-0002-4109-8847

Öğr. Gör. Dr. Esin YÜCEL, Akdeniz University, Mediterranean Civilizations Research Institute, Antalya, e-mail: esinyucel@akdeniz.edu.tr

ORCID: https://orcid.org/0000-0003-1371-8911

\begin{abstract}
The aim of this study is to determine the bibliometric properties of graduate theses published between 1987-2019 on disability tourism within the framework of various parameters. Another aim of the study is to provide the researchers with the general characteristics of the literature on disabled tourism. For this purpose, graduate theses in the field of tourism in the database of Higher Education Council were searched with the keywords "handicapped tourism", "accessible tourism" and "tourism for all". 55 theses were reached. Theses reached; years, types (master/doctorate), research patterns, keywords, spelling language, according to the institute and department were published. The theses included in the scope of the research were subjected to frequency analysis through statistical program in line with the relevant parameters and evaluated with bibliometric analysis. According to the research findings, the majority of these are master's theses. They have been written in 8 different major branches, mostly under the umbrella of social sciences institutes. It was determined that the most frequently used survey method was used as data collection tool. The findings are thought to be important in terms of presenting the general view of graduate theses on disability tourism with numerical data and filling the gap in this field.
\end{abstract}

Keywords: Bibliometry, Disabled Tourism, Accessibility, Graduate Theses.

Received: 23.10 .2019

Accepted: 04.01.2020

\title{
Suggested Citation:
}

Aksöz, E. O. and Yücel, E. (2020). Bibliometric Analysis of Graduate Thesis in Disabled Tourism, Journal of Turkish Tourism Research, 4(1): 388-404.

(C) 2020 Türk Turizm Araştırmaları Dergisi. 


\section{Gíriş}

Birleşmiş Milletler Engelli Hakları Sözleşmesine (BMEHS) göre engelli; diğer bireylere nazaran topluma tam ve etkin katılımı engelleyebilecek uzun süreli fiziksel, zihinsel, akli veya duyusal bozukluğa sahip olan kişidir. Dünyaca kabul gören engellilik tanımı, Dünya Sağlık Örgütü (WHO) tarafından daha çok tıbbî (sağlık) perspektifle yapılmış ve "Sağlık alanında -sakatlık- bir noksanlık sonucu meydana gelen ve normal sayılabilecek bir insana oranla bir işi yapabilme yeteneğinin kaybedilmesi, kısıtlanması durumu" olarak tanımlanmıştır (Öcal, 2014: 4). OECD$A B$ ve Türkiye verilerine göre, dünya nüfusunun yaklaşık \%15'i engelli bireylerden oluşmaktadır. $\mathrm{Bu}$ oran dünyada 1 milyara yakın engelli bireyin olduğu anlamına gelmektedir. Türkiye'de ise Ulusal Engelli Veri Tabanına göre engelli birey sayısı 2018 yılı itibariyle 1.559.222' dir (Ey-Der, 2019). Engelli bireyler seyahatlerinde karşılaşabilecekleri sorunları aşmada yardıma ihtiyaç duymakta ve bu sebeple onlara bu konuda yardımcı olacak birey(ler)le seyahat etmektedirler (Buhalis vd., 2012: 15). Dünya genelindeki toplam engelli nüfusuna, seyahatleri süresince onlara eşlik eden aile bireyleri, arkadaşlar, özel bakıcılar vb. da eklendiğinde, potansiyel erişilebilir turizm pazarının büyüklüğü 133 milyon olarak tahmin edilmektedir (ITB 2012; ENAT, 2012).

Engelli bireyler yeni yerler deneyimlemek istemekte ancak turizm destinasyonlarının büyük bir bölümünün "herkes için ulaşılabilir" olmaması büyük bir soruna dönüşmektedir. Bu insanlar için evleri dışında başka bir yerde konaklamak genelde zor, zahmetli ve sıkıntı vericidir. Bu gibi nedenlerle çoğu zaman daha tatile çıkmadan bu isteklerinden vazgeçebilmektedirler. Turizm hizmetleri kapsamında engellilere yönelik ulaştırma, konaklama ve diğer hizmetlerin sunumu konusunda çeşitli iyileştirmeler yapılmakla birlikte, bunların yeterli olduğunu söylemek güçtür. Büyük bir pazar olarak görülen engelli bireylerin turistik ürüne ulaşmada karşılaştıkları sıkıntıların ortadan kaldırılması, "herkes için erişilebilir" turizmin geliştirilmesi açısından oldukça önemlidir. Bir turistik ürüne erişirken ihtiyaca cevap verecek ürünün tespitinden ulaşım olanaklarına, konaklama tesisinin durumundan destinasyondaki tüm turistik faaliyetlerin ve hizmetlerin sunumuna kadar tüm aşamalar önem arz etmektedir.

Engelli insanların dünya nüfusu içindeki önemli payı ülkeleri ve örgütleri, bu insanların seyahat hakları konusunda daha duyarlı olmaya ve onların hareketliliğini artırmaya ve kolaylaştırmaya yönelik çalışmalara yönlendirmiştir (Burnett ve Baker, 2001: 6). Tüm dünyada giderek önemi artan engelli pazarının gelişimini destekleyici yönde gerek yasal gerekse çevresel düzeyde pek çok yenilik ve iyileştirme gerçekleştirilmektedir (Burnett ve Baker, 2001: 7; Richards, Pritchard ve Morgan, 2010: 1099). Bu duyarlılık ve gelişmelere paralel olarak ülkenin toplumsal inşasında önemli konuları dile getirmesi ve katkı sağlaması beklenen lisansüstü tezlerin de bu konuya giderek daha fazla odaklandığını söylemek mümkündür. Lisansüstü tezlerin genel amacının yapılan araştırma sonuçlarının bilim, toplum ve araştırma çevrelerinin yararına sunulması (YÖK, 2010) olduğu düşünüldüğünde, tezleri sadece akademik kariyer sürecinin bir parçası olarak görmek yanlış olacaktır.

Bir ülkenin biçimsel açıdan bilim insanı yetiştirme sürecinin temelini oluşturan ve toplumsal konulara katkı sağlaması beklenen lisansüstü tezlerin önemine bağlı olarak, bu çalışmaların niteliğini ortaya koyacak çalışmalar da önemlidir (Üstüner ve Cömert, 2008: 501). 1969 yılında Pritchard tarafından ortaya konan bibliyometri yönteminin amacı da bilimde yazılı iletişim sürecine ışık tutmak, belirli bir bilimsel disiplinin doğasını ve gelişimini analiz etmektir (Pritchard, 1969: 350). Bibliyometrik analizde amaç, ilgili alanda yayımlanmış olan bilimsel çalışmalardan elde edilen verilerin niceliksel analizini yapmak ve alandaki gelişim sürecini belirli çerçeveler kapsamında inceleyerek akademik alandaki entelektüel gelişime katkı sağlamaktadır (Okubo, 1997). 
Bibliyometrinin bilimsel çalışmaların gelişim sürecinin detaylı bir şekilde incelenmesine olanak tanıması çeşitli alanlarda bu yönteme olan ilgiyi artırmıştır. Yapılan çalışmaların ve akademisyen sayısının artması, bilim adamlarının ve yayın kuruluşlarının turizm yazınına sağladıkları katkıların incelenmesine duyulan merak, kişiler veya kuruluşların araştırma performansının değerlendirilmesi ihtiyacı gibi sebepler yöntemin turizm alanındaki çalışmalar için de tercih edilmesinde etken olmuştur (Temizkan vd., 2015: 395). Bu doğrultuda, turizm alanındaki bibliyometri çalışmalarının artışına paralel olarak lisansüstü çalışmalara yönelik analizlerde de artış yaşandığı gözlenmiştir. Lisansüstü tezlere yönelik bibliyometri çalışmaları incelendiğinde çalışmaların; yiyecek-içecek, gastronomi, seyahat işletmeciliği, turist rehberliği, sürdürülebilir turizm, genel turizm ve turizm coğrafyası (Jafari ve Aaser, 1988; Hall, 1991; Meyer-Arendt, 2000; Bao, 2002; Meyer-Arendt ve Justice, 2002; Turan, 2014; Aydın, 2014; Nergis, 2014; Şahin ve Acun, 2015; Tekin, 2016; Tayfun vd., 2016; Sünnetçioğlu vd., 2017; İnce vd., 2017; Alımanoğlu ve Ayazlar, 2017; Demirbulat ve Dinç, 2017; Tayfun vd., 2018; Ayaz ve Türkmen, 2018) alanlarında gerçekleştirildiği görülmektedir.

Dünyada olduğu kadar Türkiye' de de akademik olarak kurumsallaşmaya başlayan erişilebilirlik ve engelli turizminin genel görünümünü ortaya koymak için lisansüstü tezlerin önemli bir inceleme alanı olduğu düşünülmektedir. Literatür incelendiğinde engelli turizmi alanına yönelik gerçekleştirilmiş olarak sadece Cevizkaya, İlsay ve Avcıkurt'un 2000-2013 yıllarını kapsayan çalışmasına rastlanmıştır (Cevizkaya vd., 2014). Bu çalışma ile farkı ise anılan çalışmanın sadece tezleri değil makaleleri de kapsaması, incelenen tarih aralığı ve değerlendirme parametreleridir. Dolayısıyla bu çalışmadan elde edilecek bulguların engelli turizmi konusunda yayımlanan lisansüstü tezlerin genel görüntüsünü sayısal verilerle ortaya koyması ve bu alandaki boşluğu doldurması açısından önemli olduğu düşünülmektedir.

\section{KAVRAMSAL ÇERÇEVE}

Belirli bir alanda yapılmış bilimsel çalışmaların belirli aralıklarla incelenmesinin farklı yararlarından söz edilebilir. Bu tür çalışmalar, ilgili disiplinin zaman içinde gösterdiği gelişmeyi ve egemen eğilimleri anlama, var olan sorunları ortaya çıkarma, çözümüne yönelik tartısma imkânı sağlama ve gelecekteki çalışmalara ışık tutma açısından yararlıdır (Üsdiken ve Pasadeos, 1992: 250). Bilim sadece bir bilgi birikimi değil, daha çok bu birikimin devam eden sürecidir (Yıldırım, 2005: 80). Bir başka deyişle, bilimsel çalışmalar -ideal olarak- önceki çalışmaların devamı, sonraki çalışmaların öncülüdür. Bu nedenle, belirli bir disiplinde yürütülen çalışmaların toplu halde incelenmesi, geçmiş eğilimlerin ve geleceğe yönelik yol haritasının belirlenerek bilimsel sürecin izlenmesi açısından önem taşımaktadır.

Bilindiği gibi, bilimsel çalışmalar farklı biçimlerde üretilebilir. Bunlardan biri olarak tez, bilimsel iletişim sürecinde önemli bir bilgi kaynağıdır (Al ve Doğan, 2012: 354). Bilimsel üretim sürecinde tezler, ilgili disipline katkı, hazırlık ve kabul süreci açısından önemli bir çalışma türüdür. Genellikle, yüksek lisans tezleri araştırmayı öğrenme süreci olarak kabul edilirken, doktora tezlerinin ilgili alana önemli bir katkı sağlaması beklenir. Tezler sadece jüri kabulüne bağlı olmasından değil, hazırlık sürecinin de danışman denetimli olması açısından önemli bir çalışma türüdür. Bir eğitim programı sonunda hazırlanan tez, hazırlayan birey için bilimsel bir sosyalleşme sürecinin çıktısı ve akademik başarı olarak kabul edilir. Birey, akademide belirli bir uzmanlık unvanı alır. Özellikle, ilgili disipline önemli bir katkı sağlaması beklenen doktora tezleri, sonraki akademik hayatın önemli bir aşaması olarak görülür. Bu yönleri ile diğer bilimsel ürünlerden ayrılan tezler, bir disiplinle ilgili bilgi birikimine yönelik özgün ve önemli bir katkı sağlarlar (Kushowski vd., 2003: 462). 
Sosyal ve toplumsal olarak önemli konuları dile getirmesi beklenen ve kategorik bilgi kaynakları olarak değerlendirilen lisansüstü tezler ülkelerin ilgili birimlerince arşivlenir (Çakır, 2017: 315). Ülkemizde Yükseköğretim Kurulu Başkanlığı (YÖK) Ulusal Tez Merkezi, 1987 yılından itibaren üniversitelerde yapılan yüksek lisans, doktora, sanatta yeterlik ve tıpta uzmanlık tezlerini kayıt altına alarak araştırmacıların hizmetine sunmaktadır. Sistemde 2019 Ekim ayı itibariyle 558.552 tez (sanatta yeterlilik, yüksek lisans, doktora, tıpta uzmanlık ve diş hekimliği uzmanlık) mevcuttur. Bunlardan 3.323 tanesi yüksek lisans tezi, 905 tanesi doktora tezi ve 2 tanesi de sanatta yeterlilik tezi olmak üzere toplam 4.230 tanesi turizm alanındadır (YÖK, 2019).

Lisansüstü tezlerin üretilmesinde dünya genelinde belirli bir standardın yakalandığını söylemek mümkün olsa da her disiplinin kendi eğitimi, bilimsel iletişimi ve akademik kültürü bağlamında, nispeten kendine özgü eğilimleri bulunmaktadır ve bu da ilgili disiplindeki bilgi birikimini etkileyebilmektedir (Kushowski vd., 2003: 468). Bu yönüyle tez çalışmaları, ilgili disiplindeki bilimsel süreçte ortaya çıan eğilimler ve kurumsallaşma düzeyinin bir göstergesi olarak düşünülebilir.

Tezlerin incelenmesine yönelik farklı alanlarda yürütülmüş pek çok çalışmaya rastlanabilir. Tez çalışmalarında karşılaşılan incelemelerde içerik ve konu analizi, atıf analizi, araştırma yöntemi, veri toplama teknikleri gibi konularda yoğunlaşıldığ görülmektedir (Al ve Tonta, 2004: 22). Turizmin farklı alt konu başlıklarında gerçekleştirilecek bibliyometrik çalışmalar, bu alanlara ilişkin kapsamlı bir bakış açısı sağlayarak alana katkıda bulunabilecektir (Özel ve Kozak, 2012: 720). Bu amaçla bu çalışmada, gelişmekte olan ve çok disiplinli bir alan olarak engellilik ve turizm çalışmaları ile ilgili lisansüstü tezlerin, temel göstergeler ve konu analizi üzerinden değerlendirilmesi yapılmıştır.

\section{İLGİLİ ÇALIŞMALAR}

1970'lerden itibaren iletişim, bilgisayar bilimi, ekonomi, eğitim ve psikoloji gibi çeşitli disiplinlerde yaygın olarak kullanılmaya başlayan bibliyometri, zaman içerisinde tarih, sosyoloji, kütüphane ve bilgi biliminde bir alt disiplin haline gelmiştir (Lee, 2015; Zopiatis vd., 2015: 1734). Bu doğrultuda turizm alanında da bibliyometri çalışmalarına olan ilgi artmıştır. Turizme yönelik bibliyometri çalışmaları incelendiğinde ulusal ve uluslararası alanda gerçekleştirilmiş çeşitli çalışmaların olduğu görülmektedir. Uluslararası literatürdeki çalışmalar değerlendirildiğinde bu çalışmaların turizm dergilerinde yayınlanan makalelere (Palmer, 2005; Jogaratnam vd., 2005; McKercher, 2006, 2008; Jamal vd., 2008; Yonghee vd., 2009; Rogerson ve Rogerson, 2011; Nunkoo vd., 2013; Evren ve Kozak, 2014; Koç ve Boz, 2014; Köseoğlu vd., 2015; Ruhanen vd., 2015; Cheng vd., 2016; Köseoğlu vd., 2016, ; Sánchez vd., 2017; Okumuş vd., 2018) ve lisansüstü tezlere (Jafari ve Aaser, 1988; Hall, 1991; Meyer-Arendt, 2000; Bao, 2002; Meyer-Arendt ve Justice, 2002) yönelik olduğu görülmektedir.

Türkiye'de turizmde bibliyometri alanına olan ilgi 1990'lı yıllardan itibaren artmış ve bibliyometrik teknikler kullanılarak araştırmalar analiz edilmiştir (Evren ve Kozak, 2014). Turizm alanındaki bibliyometri çalışmaları incelendiğinde çalışmaların genellikle dergilerde yayınlanan makaleler kapsamında olduğu ve bu çalışmalarda makalenin konusu, yazarlar, kullanılan yöntemler, atıf sayısı, kurumsal katkı gibi çeşitli parametrelerin incelendiği görülmektedir (Çiçek ve Kozak, 2012; Özel ve Kozak, 2012; Zencir ve Kozak, 2012; Yüncü ve Kozak 2012; Şakar ve Cerit 2013; Çakıcı vd., 2013; Evren ve Kozak, 2014; Türktarhan, 2014; Cevizkaya vd., 2014; Bayram vd., 2017; Sökmen ve Özkanll, 2018).

Turizm alanındaki makalelere yönelik bibliyometri çalışmalarının yanında, son yıllarda lisansüstü tezlere ilişkin bibliyometri çalışmalarının sayısında da artış yaşanmıştır. Bu 
çalışmalarda lisansüstü tezlerin bibliyometrik özellikleri belirli konular ve çeşitli parametreler bağlamında incelenmiştir. Aşağıda özetlendiği üzere turizmdeki lisansüstü tezlere yönelik bibliyometri çalışmaları incelendiğinde araştırmacıların benzer konular üzerinde çalıştığı ancak farklı sonuçlara ulaştığı görülmektedir.

\begin{tabular}{|l|l|l|l|}
\hline $\begin{array}{l}\text { Turizm alanındaki } \\
\text { lisanüstü tezler }\end{array}$ & Ylllar & $\begin{array}{l}\text { İncelenen } \\
\text { tez sayısı }\end{array}$ & Ulaşılan sonuçlar \\
\hline Nergis (2014) & $1990-2013$ & 2.348 & $\begin{array}{l}\text { En fazla yüksek lisans tezinin Gazi Üniversitesi } \\
\text { SBE, en fazla doktora tezinin Dokuz Eylül } \\
\text { Üniversitesi SBE bünyesinde hazırlandı̆ı }\end{array}$ \\
\hline Turan (2014) & $1984-2013$ & 1.670 & $\begin{array}{l}\text { En fazla yüksek lisans tezinin İstanbul } \\
\text { Üniversitesi SBE ve Turizm İşletmeciliği } \\
\text { Anabilim Dalı bünyesinde hazırlandı̆1 }\end{array}$ \\
\hline Tekin'in (2016) & $1984-2015$ & 1.370 & $\begin{array}{l}\text { Tezlerin çoğunlukla yüksek lisans düzeyinde } \\
\text { olduğu ve Gazi Üniversitesi SBE bünyesinde } \\
\text { hazırlandığ1 }\end{array}$ \\
\hline Tayfun vd. (2016) & $1985-2016$ & 367 & $\begin{array}{l}\text { Tezlerin çoğunlukla yüksek lisans düzeyinde } \\
\text { olduğu ve eğitim bilimleri enstitüsü çatısı altında } \\
\text { hazırlandığ1 }\end{array}$ \\
\hline
\end{tabular}

Turizm alanına yönelik gerçekleştirilmiş olan bu çalışmalar değerlendirildiğinde araştırmacıların yararlandığı parametrelerde ve elde edilen sonuçlarda farklılıklar bulunmaktadır. Tezlerin yayın yıllarının neredeyse aynı dönemleri kapsamasına rağmen, Tekin'in (2016) çalışmasında 1.370 tez, Tayfun vd.'nin (2016) çalışmasında ise 367 tez incelenmiştir. Bu açıdan her iki çalışmanın tez sayısında sayısal açıdan önemli farklılıklar bulunmaktadır.

Turizmin belirli alanına yönelik olarak lisansüstü tezlere ilişkin yapılan bibliyometri çalışmalarında da araştırmacılar temelde benzer konuları incelemiş fakat farklı sonuçlar elde etmişlerdir.

\begin{tabular}{|c|c|c|c|c|}
\hline & & Yillar & $\begin{array}{l}\text { İncelenen tez } \\
\text { sayisı }\end{array}$ & Ulaşılan sonuçlar \\
\hline \multirow{2}{*}{$\begin{array}{l}\text { Yiyecek- } \\
\text { içecek } \\
\text { işletmeciliği } \\
\text { alanındaki } \\
\text { lisansüstü } \\
\text { tezler }\end{array}$} & Aydın'ın (2014) & $\begin{array}{l}1988- \\
2013\end{array}$ & 179 & $\begin{array}{llrr}\text { Tezlerin } & \text { büyük } & \text { ölçüde } & \text { Gazi } \\
\text { Üniversitesi } & \text { SBE Turizm İşletmeciliği } \\
\text { Anabilim } & \text { Dalı çatısı altında } \\
\text { hazırlandığı } & & \\
\end{array}$ \\
\hline & Tayfun vd. (2018) & $\begin{array}{l}1990- \\
2018\end{array}$ & 164 & $\begin{array}{l}\text { Tezlerin büyük ölçüde Turizm } \\
\text { İşletmeciliği ile Turizm İşletmeciliği ve } \\
\text { Otelcilik Anabilim Dalı çatısı altında } \\
\text { hazırlandığı }\end{array}$ \\
\hline \multirow{2}{*}{$\begin{array}{l}\text { Gastronomi } \\
\text { alanındaki } \\
\text { lisansüstü } \\
\text { tezler }\end{array}$} & $\begin{array}{l}\text { Sünnetçioğlu vd. } \\
\text { (2017) }\end{array}$ & $\begin{array}{l}1987- \\
2017\end{array}$ & 33 & \multirow{2}{*}{$\begin{array}{l}\text { Lisansüstü tezlerde nicel araştırma } \\
\text { yöntemlerinin uygulandığı }\end{array}$} \\
\hline & $\begin{array}{l}\text { Ayaz ve Türkmen } \\
(2018)\end{array}$ & $\begin{array}{l}1999- \\
2017\end{array}$ & 45 & \\
\hline
\end{tabular}

Yiyecek-içecek işletmeciliği alanındaki her iki çalışmada tezlerin büyük ölçüde Sosyal Bilimler Enstitüsü (SBE) ve Turizm İşletmeciliği Anabilim Dalı bünyesinde hazırlanması açısından benzer sonuçlara ulaşılmış fakat bununla beraber incelenen tez sayıları farklılık göstermiştir. 
Gastronomi alanındaki her iki çalışmada incelenen parametreler ve tez sayıları farklılık göstermekle beraber lisansüstü tezlerde nicel araştırma yöntemlerinin uygulandığı bulgusu benzerdir.

Disiplinler arası nitelikte olan turizmle ilgili olarak diğer bibliyometri çalışmaları incelendiğinde, konuların çeşitlilik gösterdiğini söylemek mümkündür. Yukarıda özetlenen genel turizm, gastronomi ve yiyecek içecek işletmeciliği alanlarının dışındaki lisansüstü tezleri inceleyen bibliyometri çalışmaları aşağıda özetlenmiştir.

\begin{tabular}{|c|c|c|c|c|}
\hline & Yillar & Alan & $\begin{array}{l}\text { İncelenen } \\
\text { tez sayisı }\end{array}$ & Ulaşılan sonuçlar \\
\hline Arıca (2014) & $1988-2013$ & $\begin{array}{l}\text { Seyahat } \\
\text { işletmeciliği }\end{array}$ & 220 & $\begin{array}{l}\text { Tezlerin çoğunluğun SBE kapsamında } \\
\text { ve İstanbul Üniversitesi bünyesinde } \\
\text { hazırlandığı, önemli bir bölümünün } \\
\text { yüksek lisans tezi düzeyinde olduğu, } \\
\text { pazarlama alanında gerçekleştirildiği ve } \\
\text { büyük ölçüde nicel araştırma } \\
\text { yöntemlerinin tercih edildiği }\end{array}$ \\
\hline $\begin{array}{l}\text { Şahin ve Acun } \\
\text { (2015) }\end{array}$ & 1989-2015 & $\begin{array}{l}\text { Turist } \\
\text { rehberliği }\end{array}$ & 38 & $\begin{array}{l}\text { Tezlerin en fazla Balıkesir Üniversitesi } \\
\text { bünyesinde hazırlandığı }\end{array}$ \\
\hline $\begin{array}{l}\text { Alımanoğlu ve } \\
\text { Ayazlar }\end{array}$ & $2003-2016$ & Kirsal turizm & 20 & $\begin{array}{l}\text { Yüksek lisans tez çalışmalarının, } \\
\text { doktora düzeyindeki tez çalşsmalarına } \\
\text { nazaran daha fazla olduğu ve tezlerin } \\
\text { çoğunlukla uygulamalı olduğu }\end{array}$ \\
\hline $\begin{array}{l}\text { Demirbulat ve } \\
\text { Dinç (2017) }\end{array}$ & 1987-2015 & $\begin{array}{l}\text { Sürdürülebilir } \\
\text { turizm }\end{array}$ & 62 & $\begin{array}{l}\text { Tezlerin çoğunlukla üniversitelerin } \\
\text { Turizm İşletmeciliği Anabilim Dalı } \\
\text { çatısı altında hazırlandığı, üniversiteler } \\
\text { arasında en fazla lisansüstü tezin } \\
\text { İstanbul Üniversitesi bünyesinde } \\
\text { yayımlandığı }\end{array}$ \\
\hline İnce vd. (2017) & $1990-2016$ & $\begin{array}{l}\text { Turizm } \\
\text { pazarlaması }\end{array}$ & 177 & $\begin{array}{l}\text { En fazla tezin } 2015 \text { yılında yazıldığı, } \\
\text { tezlerin düzeyinin yüksek lisans olup } \\
\text { Turizm İşletmeciliği Anabilim Dalı'nda } \\
\text { gerçekleştirildiği ve en çok tezin Gazi ve } \\
\text { Balıkesir } \\
\text { hazırlandığı. }\end{array}$ \\
\hline Kozak (2001) & $1972-1998$ & $\begin{array}{l}\text { Turizm } \\
\text { pazarlaması }\end{array}$ & 131 & $\begin{array}{l}\text { En fazla turizm pazarlaması konulu } \\
\text { tezin, İstanbul Üniversitesi (25) ve Gazi } \\
\text { Üniversitesinde (24) yayımlandığı. }\end{array}$ \\
\hline
\end{tabular}

Turizm alanındaki lisansüstü tezlere ilişkin bibliyometri çalışmaları değerlendirildiğinde araştırmalar genel turizm, gastronomi, yiyecek-içecek, pazarlama, kırsal turizm, turist rehberliği alanlarına yöneliktir. Araştırmalarda incelenen parametreler önemli ölçüde benzerlik gösterse de benzer alanlardaki çalışmalarda yıl dağılımı, tez sayısı, işlenen konular ve elde edilen sonuçların farklılık gösterdiği görülmektedir. Ancak, yapılan incelemeler neticesinde turizmde çeşitli konularda ve alanlarda bibliyometri çalışması bulunmasına rağmen engellilik ve engelli turizmine yönelik aynı yıl aralığını ve parametrelerini kapsayan bibliyometri çalışmasına rastlanmamıştır. Dolayısıyla çalışmanın amacı, bu alan yazının gelişim sürecini ortaya koymak ve yüksek lisans ve doktora tezlerini bibliyometrik özellikleri açısından incelemektir. Bu bağlamda, Türkiye'de erişilebilirlik ve engelsiz turizmle ilgili lisansüstü tezlerin profilini çok disiplinli bir yaklaşımla ortaya koymayı amaçlayan bu çalışmanın sorusu: Erişilebilirlik ve 
engelsiz turizm alanında tamamlanan tezlerin türlerine (yüksek lisans/doktora), yıllara, enstitülere, anabilim dallarına, araştırma desenlerine, anahtar kelimelerine ve yazım diline göre dağılımı nasıldır?

\section{YÖNTEM}

Araştırma sorularına yanıt bulmak amacıyla, bibliyometri analizinden yararlanılmıştır. Bu çalışmada, bibliyometrinin uygulanacağı veri kaynakları dokümanlardır. Dokümanlarda hedeflenen olgu veya olgular hakkında bilgi içeren yazılı materyaller incelenir. Yöntemin zayıf yönlerinden olan doküman seçiminde yanlılık ve kodlama zorluğu, bu çalışmadaki üç araştırmacının çapraz kontrolleri ve uzman görüşleri ile en aza indirilmeye çalışılmıştır. Doküman incelemenin bir diğer zorluğu da eksik veridir (Yıldırım ve Şimşek, 2013: 65-68). Bu çalışmada, paylaşıma kapalı 4 tane tezin zorunlu olarak araştırmaya dâhil edilememesi önemli bir sınırlılıktır. Bilimsel iletişimin kalitesini arttırmak ve bilimin işlevini sağlıklı biçimde sürdürebilmesi için istisnaî durumlar hariç, ilkesel olarak açık erişim önerilmektedir (YÖK, 2010). Nitel veri ve analizine dayalı olan bu çalışmada farklı uzman kişilerin görüşlerinin alınması ile iç geçerliliği, araştırma yönteminin detaylı sunumu ile güvenilirliği arttırmaya (Şencan, 2005: 84) özen gösterilmiştir.

Bu çalışmada YÖK Ulusal Tez Merkezi veri tabanında yer alan, erişilebilirlik ve engelsiz turizmle ilgili 31.12.2018 tarihine kadar tamamlanmış yüksek lisans ve doktora tezleri incelenmiştir. Doküman incelemelerinde hangi belgelerin önemli olduğu ve veri kaynağı olarak kullanılabileceği, araştırma problemi ile ilgilidir (Yıldırım ve Şimşek, 2013: 65). Bilindiği gibi, engellilik çok farklı anabilim dallarınca yararlanılan bir sözcüktür. Bu çalışmada, engelsiz turizmin genel görünümünü ortaya koyabilmek için, tezlerin seçimi ve değerlendirilmesine yönelik bir çerçeve belirlenmiştir. Bu amaçla öncelikle, erişilebilirlik ve engelsiz turizm ilişkisi ile ilgili çalışmalarda yararlanılabilecek arama terimleri ve konu başlıklarını belirlemek üzere, erişilebilirlik ve engelsiz turizm alanında önemli düzeyde uzmanlığı bulunan üç kişinin görüşüne başvurulmuştur.

Uzmanlardan gelen arama terimi önerileri incelendiğinde, sözcük/ifade birliği sağlanarak beş farklı arama terimi (engelli turizmi/erişilebilirlik/engelsiz turizm/ulaşılabilirlik/herkes için turizm) ortaya çıkarılmıştır. Tezlerin konularına göre sınıflandırılmasında, ağırlıklı araştırma alanı dikkate alınmıştır.

Araştırma alanı çerçevesini belirlemede yanıt aranan bir diğer soru da engelsiz turizme hangi ölçüde yer veren tezlerin incelemeye alınacağıdır. Tahmin edileceği gibi arama terimleriyle birlikte düşünüldügü̈nde, çok farklı alanlardan çok sayıda tezle karşılaşılabilir. Disiplinler arası nitelikteki çalışmadan söz edebilmek için farklı disiplinlerin kabul edilebilir ölçüde katkı sağlaması beklenir. Ancak bu konuda kesin bir ölçütten söz etmek de zordur. Bu çalışmada ölçülebilir bir değer olarak, tezin kavramsal bölümlerinden en az bir tam bölümün engelsiz turizm ile ilgili konulara ayrılmış olmasına karar verilmiştir.

\section{BULGULAR}

Türkiye'de engelsiz turizm alanında tamamlanmış lisansüstü tezlerin tür ve yazım diline göre dağılımları Tablo 1'de görülmektedir. 
Tablo 1. Tür ve Yazım Diline Göre Tezlerin Dağılımı

\begin{tabular}{lccc}
\hline & & Sayı & $\mathbf{\%}$ \\
\hline Tez türü & Yüksek lisans & 36 & 70,58 \\
\cline { 2 - 4 } & Doktora & 15 & 29,42 \\
\hline Yazım dili & Türkçe & 46 & 90,19 \\
\cline { 2 - 4 } & İngilizce & 5 & 9,81 \\
\hline
\end{tabular}

51 tezin $36^{\prime}$ sı $(\% 70,58)$ yüksek lisans tezi, 15'i $(\% 29,42)$ ise doktora tezidir. Yazım diline göre tezlerin 46 'sı $(\% 90,19)$ Türkçe, 5'i $(\% 9,81)$ İngilizcedir.

Türkiye'de engelsiz turizm alanında tamamlanmış yüksek lisans ve doktora tezleri ve yayın yıllarına göre dağılımları Tablo 2'de görülmektedir.

Tablo 2. Tezlerin Tür ve Yıllara Göre Dağılımı

\begin{tabular}{|c|c|c|c|c|}
\hline Y11 & Yüksek Lisans & Doktora & Toplam & $\%$ \\
\hline 2018 & 3 & 2 & 5 & 9,86 \\
\hline 2017 & 2 & 2 & 4 & 7,84 \\
\hline 2016 & 2 & 1 & 3 & 5,88 \\
\hline 2015 & 2 & 1 & 3 & 5,88 \\
\hline 2014 & 2 & 1 & 3 & 5,88 \\
\hline 2013 & 2 & 1 & 3 & 5,88 \\
\hline 2012 & 2 & 1 & 3 & 5,88 \\
\hline 2011 & 2 & 1 & 3 & 5,88 \\
\hline 2010 & 2 & - & 2 & 3,92 \\
\hline 2009 & 2 & - & 2 & 3,92 \\
\hline 2008 & 1 & 1 & 2 & 3,92 \\
\hline 2007 & 1 & - & 1 & 1,96 \\
\hline 2006 & 2 & - & 2 & 3,92 \\
\hline 2005 & 1 & 1 & 2 & 3,92 \\
\hline 2004 & 1 & 1 & 2 & 3,92 \\
\hline 2003 & 1 & - & 1 & 1,96 \\
\hline 2002 & 1 & - & 1 & 1,96 \\
\hline 2001 & 1 & - & 1 & 1,96 \\
\hline 2000 & 1 & - & 1 & 1,96 \\
\hline 1999 & 1 & - & 1 & 1,96 \\
\hline 1998 & 1 & 1 & 2 & 3,92 \\
\hline 1997 & 1 & - & 1 & 1,96 \\
\hline 1996 & 1 & - & 1 & 1,96 \\
\hline 1995 & 1 & - & 1 & 1,96 \\
\hline 1991 & 1 & - & 1 & 1,96 \\
\hline Toplam & 37 & 14 & 51 & $\% 100,00$ \\
\hline
\end{tabular}

$\mathrm{Bu}$ araştırmada belirlenen ölçütlere göre, engelsiz turizm ile ilgili yüksek lisans tezi ilk olarak 1991'de, doktora tezi ise 1998 yılında yazılmıştır. Yüksek lisans tezinin en çok yazıldığı yıl üç tez ile $2018^{\prime}$ dir. Doktora tezi ise hem $2017^{\prime}$ de hem de $2018^{\prime}$ de ikişer adet yazılmıştır. Toplamda ise en çok tez üretim yılı beş adet tez ile 2018'dir $(\% 9,86)$. 
İncelenen tezlerin enstitü ve anabilim dallarına göre dağılımına ilişkin bulgular Tablo 3 'te sunulmaktadir.

Tablo 3. Enstitü ve Ana Bilim Dallarına Göre Tezlerin Dağılımı

\begin{tabular}{llcc}
\hline & Enstitü Adı & Sayı & $\mathbf{\%}$ \\
\hline 1 & Sosyal Bilimler Enstitüsü & 33 & 64,70 \\
\hline 2 & Eğitim Bilimleri Enstitüsü & 12 & 23,12 \\
\hline 3 & Sağlık Bilimleri Enstitüsü & 6 & 11,76 \\
\hline & Toplam & 51 & $\mathbf{\% 1 0 0}$ \\
\hline & Anabilim Dalı & & \\
\hline 1 & Turizm İşletmeciliği (veya Turizm ve Otel İşletmeciliği) & 20 & 39,21 \\
\hline 2 & İşletme & 7 & 13,72 \\
\hline 3 & Turizm İşletmeciliği Eğitimi & 6 & 11,76 \\
\hline 4 & Seyahat İşletmeciliği & 5 & 9,80 \\
\hline 5 & Beden Eğitimi & 4 & 7,84 \\
\hline 6 & İç Mimarlı/İç Mekân Tasarımı & 3 & 5,88 \\
\hline 7 & Rekreasyon & 2 & 3,92 \\
\hline 8 & Pazarlama & 1 & 1,96 \\
\hline & Toplam & $\mathbf{5 1}$ & $\mathbf{\% 1 0 0}$ \\
\hline
\end{tabular}

Tezlerin tamamlandığı enstitüler incelendiğinde, yaklaşık \%65'i Sosyal Bilimler Enstitülerinde, yaklaşı \%23'ü Eğitim Bilimleri Enstitülerinde ve \%12'si ise Sağllk Bilimleri Enstitülerinde tamamlanmıştır.

Anabilim dallarına göre dağılıma bakıldığında ise, engelsiz turizm ile ilgili tezler 8 ayrı anabilim dalında hazırlanmıştır. Turizm işletmeciliği ana bilim dalında 20 adet tez tamamlanırken, işletme anabilim dalı 7 ve turizm işletmeciliği eğitimi anabilim dalı 6 tez ile ikinci ve üçüncü sırada en çok tez yazılan ana bilim dalları olmuşlardır.

İncelenen tezlerin araştırma desenlerine göre dağılımına ilişkin bulgular Tablo 4'te sunulmaktadır.

Tablo 4. Araştırma Desenlerine Göre Tezlerin Dağılımı

\begin{tabular}{lcc}
\hline Araştırma Deseni & $\mathbf{n}$ & $\mathbf{\%}$ \\
\hline Nicel veriye dayalı & 24 & 47,05 \\
\hline Nitel veriye dayalı & 18 & 35,29 \\
\hline Karma (nicel+nitel) & 8 & 15,68 \\
\hline Doküman analizi & 1 & 1,96 \\
\hline Toplam & $\mathbf{5 1}$ & $\mathbf{0 1 0 0}$ \\
\hline
\end{tabular}

Araştırma desenine göre 24 tez ile en çok nicel veriye dayalı araştırmanın yapıldığı görülse de nitel (18 tez) ve karma yönteme dayalı ( 8 tez) tezlerin de yazıldığı tespit edilmiştir. Doküman analizi/tarihî belgelere dayalı sadece bir adet tez yazılmıştır.

Anahtar kelimeler, bir çalışmanın başlığından sonra hızla fikir verebilen bir diğer göstergedir. Engelsiz turizm ile ilgili tezlerin anahtar kelimelerine göre dağılımı Tablo 5'te sunulmaktadır. 
Tablo 5. Anahtar Kelimelerle İlgili Bulgular

\begin{tabular}{lcc}
\hline Anahtar kelimeler & S1klık & Toplam \\
\hline Engelli Turizm & 18 & \\
\cline { 1 - 2 } Erişilebilirlik & \multirow{2}{*}{51} \\
\hline Engelsiz Turizm & 12 & 10 \\
\hline Ulaşılabilirlik & 9 & \\
\hline Herkes için Turizm & 2 & \\
\hline
\end{tabular}

Engelsiz turizm ile ilgili tezlerin anahtar kelimelerinin dağılımına bakıldığında engelli turizmi (18), erişilebilirlik (12), engelsiz turizm (10), ulaşılabilirlik (9) ve herkes için turizm (2)'dir.

$\mathrm{Bu}$ çalışmada son yıllarda yaşamda olduğu kadar, akademide de giderek ilgi gören engelsiz turizmin gelişimi çok disiplinli bir yaklaşımla lisansüstü tezler aracıllğı ile incelenmiştir. YÖK ulusal tez veri tabanında yapılan incelemeye göre, 31.12.2018 itibariyle, tezin en az bir tam bölümünün engelsiz turizm ile ilgili olduğu, açık erişim imkânı bulunan 51 tez belirlenmiştir. Bu alandaki tez sayısı şüphesiz daha fazladır, ancak tezlerin tamamının inceleme imkânı olmayacağından, araştırma alanını sadece erişimdeki tezlerin oluşturması önemli bir sınırlılıktır. Araştırmaya uygun olan tezler bibliyometrik analiz ile türü, yılı, anabilim dalı, enstitüsü, araştırma deseni, anahtar kelimeler ve yazım dili olarak belirlenen yedi parametre boyutuyla incelenmiştir.

\section{TARTIŞMA, SONUÇ VE ÖNERILLER}

Son yıllarda engellilik ve turizm ilişkisine vurgu yapan araştırmaların özellikle uluslararası yazında arttığını söylemek mümkün görünmektedir. Uluslararası yazında gözlemlenen bu gelişme, ulusal yazında da karşılık bulmuş ve son yıllarda konusu ve/ya araştırma alanı engellilik ve turizm olan tezlerde kayda değer bir artış olduğu gözlemlenmiştir. Aynı şekilde turizm alanında bibliyometrik analiz çalışmaları da artış göstermiş fakat engellilik ve turizm ile ilgili lisansüstü tezleri inceleyen bir bibliyometrik çalışmaya rastlanılmamış olması bu çalışmanın çıkış noktası olmuştur.

Çalışmada engelsiz turizm alanına yönelik olarak hazırlanmış olan lisansüstü tezlerin gelişim süreci ve bibliyometrik özelliklerinin incelenmesi amaçlanmıştır. Bu kapsamda YÖKTEZ veri tabanında yer alan 51 lisansüstü tez yayınlandığı yıl, tezin türü (yüksek lisans ve doktora), enstitü, anabilim dal, yazım dili, anahtar kelimeler ve uygulanan araştırma yöntemi, kapsamında incelenerek bibliyometrik özellikleri ortaya konulmuştur.

Engelsiz turizm alanında yayınlanmış olan lisansüstü tezlerin 1991 yılından itibaren hazırlanmaya başlandığı ve tez sayısında 2010'lu yıllardan itibaren artış yaşandığı elde edilen bulgular neticesinde ortaya çıkmıştır. Elde edilen bu bulgulardan yola çıkarak alana yönelik tezlerin artışında hem turizm hem de erişilebilirlik alanındaki akademik ve sektörel açıdan yaşanan gelişmelerin etkili olduğu söylenebilir.

Araştırmada engelsiz turizm alanında hazırlanmış tezlerin büyük oranda yüksek lisans düzeyinde ve Sosyal Bilimler Enstitüsü bünyesinde hazırlandığı belirlenmiştir. Aydın (2014), Arıca (2014), Sünnetçioğlu (2017), Alımanoğlu ve Ayazlar (2017), İnce vd. (2017), Tayfun vd.'nin (2018) çalışmalarında da benzer sonuçlar elde edilmiştir. Engelsiz turizmim disiplinler arası bir alan olarak birden fazla disiplin ve anabilim dalıyla ilişkili olması özelliği tezlerin önemli ölçüde Sosyal Bilimler Enstitüsü altında hazırlanmasının gerekçesi olarak gösterilebilir. Engelsiz turizm kavramına 8 farklı anabilim dalı altında yer verildiği ve Turizm İşletmeciliği Anabilim Dalı 
bünyesinde hazırlanan tezlerin sayısal olarak öne çıktı̆̆ çalışmada elde edilen bir diğer sonuçtur. Elde edilen bu sonuç Aydın (2014), Turan (2014), Demirbulat ve Dinç (2017), İnce vd. (2017), Tayfun vd. (2018) ve Ayaz ve Türkmen'in (2018) çalışmalarına benzerlik göstermektedir. 8 farklı anabilim dalı altında engelsiz turizm kavramının incelenmesi, erişilebilirlik ve turizmin karmaşık yapısının çeşitli anabilim dallarının dikkatini çektiğini göstermektedir. Bununla birlikte tezlerin "Turizm İşletmeciliği Anabilim Dalı" altında hazırlanmış olması engelsiz turizm kavramının turizm açısından önemini ortaya koymaktadır. Lisansüstü tezler işlenen konular bağlamında da değerlendirildiğinde destinasyon alanında hazırlanmış tezlerin çoğunlukla turizm temelli çalışmalar olduğu belirlenmiştir. Elde edilen bu sonuç Nergis'in (2014) çalışmasıyla benzerlik göstermektedir. Çalışmada ele alınan tezlerin büyük bir çoğunluğu Türkçe dilinde hazırlanmıştır. Yabancı dilde hazırlanan tez sayısı oldukça azdır.

Lisansüstü tezlerde uygulanan yöntemlerde yüksek lisans ve doktora düzeyindeki araştırmacılar tarafından çoğunlukla nicel araştırma yöntemlerinin tercih edildiği çalışmanın bir diğer sonucudur. Elde edilen bu sonuç Aydın (2014), Arıca (2014), Sünnetçioğlu vd. (2017) ve Ayaz ve Türkmen'in (2017) çalışmalarıyla da benzerlik göstermektedir. Bununla birlikte, araştırmalarda nicel yaklaşımlarından büyük ölçüde yararlanılması pozitivist paradigmanın araştırmalar üzerinde etkili olduğunun bir göstergesidir. Öte yandan nicel yöntemlerin daha çok yüksek lisans ve nitel yöntemlerin de daha çok doktora düzeyindeki tezlerde tercih edildiği çalışmada ulaşılan bir diğer sonuçtur. Elde edilen bu sonuç Tayfun vd.'nin (2018) çalışmasıyla benzerlik göstermektedir. $\mathrm{Bu}$ kapsamda, doktora düzeyindeki araştırmacıların daha derinlemesine araştırma konuları üzerinde yoğunlaştığı söylenebilir.

Yapılan önceki bibliyometrik çalışmalar incelendiğinde; turizm alanında yapılan lisansüstü tezler, gastronomi, girişimcilik, sürdürülebilir turizm, turist rehberliği, örgütsel davranış vb. olarak ele alınmış ve belirli parametreler ışığında incelenmiştir. Parametreler arasında, örneklem sayısı, araştırma yöntemi, örneklem çeşidi vb. bulunmaktadır. Bu doğrultuda ileride yapılacak çalışmalarda parametre sayılarının arttırılıp çeşitlendirilerek çalışılması araştırmaların niteliğini arttırabilir. Ayrıca, araştırmacılar ileride yapacakları çalışmalarda lisansüstü tezler yanında makaleler, kitap, kitap bölümü ya da kongrelerde sunulan bildirileri de inceleme kapsamina alarak bibliyometri çalışmalarının niteliğine olumlu katkı sağlayabilirler.

Oviedo-Garcia'nın (2016: 589) ifade ettiği gibi, bir alanın olgunlaşmaya başlamasının ilk aşamasının zorluklarla dolu olması doğal kabul edilir. Turizmin ekonomik önemi nedeniyle, uzun yıllar disiplinin gelişimine yön veren ekonomi ve işletme zemininin bir süredir aşılmakta olduğu ve disiplinler arası niteliğinin giderek önem kazandığı görülmektedir. Benzer bir durumu engelsiz turizm için de söylemek mümkündür. Anahtar kelimeler bu çalışmada beş adet ile sınırlandırılmıştır. Bu durum daha alanın yeni olması ve engelli turizm mi? yoksa engelsiz turizm mi? sorularının sorulmasından kaynaklanmaktadır. Bu çalışmada en çok engelli turizm anahtar kelimesine rastlanmıştır.

Bu çalışmadaki sonuçlar ışığında engelsiz turizme olan ilginin yıllar itibari ile arttığını söylemek mümkündür. Özellikle son on yılda engelsiz turizm kavramının önem kazandığı, konunun yüksek lisans ve doktora tezlerinde önceki yıllara göre daha fazla çalışıldığı ve farkındalık yaratılmak istendiği söylenebilir. Engelsiz turizmin bilgi alanı olarak büyümesi ve bu konuda yüksek lisans ve/veya doktora tezi yazan akademisyen sayısının artması bu alana ve toplumsal anlamda da engellilere olan bakış açısını olumlu anlamda değiştirebilir. Bu bağlamda turizmin farklı alt konu başlıklarında gerçekleştirilecek bibliyometrik çalışmalar, kapsamlı bir bakış açısı sağlayarak ilgili alana katkıda bulunabilecektir. Bu önem doğrultusunda yapılan bu çalışma ile engelsiz turizmle ilgili yapılan çalışmaların yıllar itibariyle artışı ve en çok hangi anahtar kelimeler altında ve hangi enstitü/üniversitede yayımlandığı hakkındaki bilgilere ulaşabilirler. Ayrıca, çalışmanın engelsiz turizm konusunda araştırmacılara yol göstermesi mümkündür. 
Bu çalışmanın hem lisansüstü eğitim yapmayı isteyen öğrencilere hem de ilgili literatüre katkı sağladığı düşünülmektedir. Araştırmada, engelsiz turizm ile ilgili yazılan lisansüstü tezlerde hangi veri toplama aracının kullanıldığı, hangi kitleden daha fazla veri toplandığı, hangi üniversitelerde daha fazla tez yazdırıldığı, tez türüne göre hangi araştırma yaklaşımlarının daha fazla benimsendiği, tezlerin özet bölümünde hangi unsurlara ne kadar yer verildiği ve tezlerde hangi tür kaynaklara ne kadar yer verildiği hakkında bilgiler sunulmaktadır. Öte yandan engelsiz turizm alanında yapılmış herhangi bir bibliyometri çalışmasına rastlanmamış olması nedeniyle bu araştırmanın önem arz edeceği düşünülmektedir. Bu çalışmanın diğer bir önemli katkısı engelsiz turizm gibi gelişmekte olan bir disiplinin mevcut zenginliği içinde gelişimine dikkat çekmek ve bunun için lisansüstü tezlerinden yola çıkarak teorik birikimi ortaya koymaktır. Araştırmada belirtilmesi gereken en önemli sınırlılık, araştırmada sadece YÖKTEZ'de bulunan ve erişime açık olan tezlerin incelemeye alınmasıdır. Son olarak araştırmacılara, bu çalışmada kullanılan parametrelerle farklı alanlardaki kitapları, makaleleri, tezleri ve bildirileri incelemeleri önerilmektedir.

\section{KAYNAKÇA}

Al, U. ve Doğan, G. (2012). Hacettepe Üniversitesi Bilgi ve Belge Yönetimi Bölümü Tezlerinin Atıf Analizi, Türk Kütüphaneciliği, 2: 349-369.

Al, U. ve Tonta, Y. (2004). Atıf Analizi: Hacettepe Üniversitesi Kütüphanecilik Bölümü Tezlerinde Atıf Yapılan Kaynaklar, Bilgi Dünyası, 5(1): 19-47.

Alımanoğlu, Ç. ve Ayazlar, G. (2017). Bibliometric Study on Postgraduate Thesis Studies on Rural Tourism in Turkey (2003- 2016), Uluslararası Kırsal Turizm ve Kalkınma Dergisi, 1(1): 6-12.

Arıca, R. (2014). Seyahat İşletmeciliği Literatürünün Gelişim Süreci: Türkiye'de Hazırlanan Lisansüstü Tez Çalışmalarının Bibliyometrik Olarak İncelenmesi, VII. Lisansüstü Turizm Öğrencileri Araştırma Kongresi, 04-05 Nisan 2014, Kuşadası, Aydın, 446-462.

Ayaz, N. ve Türkmen, B. (2018). Yöresel Yiyecekleri Konu Alan Lisansüstü Tezlerin Bibliyometrik Analizi. Gastroia: Journal of Gastronomy and Travel Research, 2(1): 22-38. DOI: 10.32958/gastoria. 411345

Aydın, B. (2014). Yükseköğretim Kurulu Tez Merkezinde (Yöktez) Yiyecek İçecek İşletmeciliği Alanında Kayıtlı Bulunan Tezlerin Bibliyometrik Analizi, Disiplinlerarası Akademik Turizm Dergisi, 2(1): 23-38.

Bao, J. (2002). Tourism geography as the subject of doctoral dissertations in China, 1989-2000, Tourism Geographies: An International Journal of Tourism Space, Place and Environment, 4: 148- 152.

Bayram, G. E., T., Bayram, A. T. ve Karaçar, E. (2017). Sürdürülebilir Turizm: Bibliyometrik Analiz, 1st International Sustainable Tourism Congress, Kastamonu-Turkey (November 23-25), 179

Buhalis, D., Darcy, S. and Ambrose, I. (2012). Best Practice in Accessible Tourism: Inclusion, Disbility, Ageing Population and Tourism, ISBN:-15 978184541 2531, Chanel View Publication, USA.

Burnett, J. J., and Baker, B. H. (2001). Assessing the travel-related behaviors of the mobilitydisabled consumer, Journal of Travel Research, 40: 4-11.

Cevizkaya, G., İlsay, S. ve Avcıkurt, C. (2014). Turizm Alanyazınında Engelliler ile İlgili Çalışmaların Bibliyometrik Profili (2000-2013), Gazi Üniversitesi Turizm Fakültesi Dergisi, 1(2): 101108 
Cheng, M., Edwards, D., Darcy, S. and Redfern, K. (2016). A Tri-ethod Approach to A Review of Adventure Tourism Literature: Bibliometric Analysis, Content Analysis, and A Quantitative Systematic Literature Review, Journal of Hospitality \& Tourism Research, 42(6): 997 - 1020.

Çakıcı, A. C., Yıldırım, O. ve Karacaoğlu, S. (2013). Ulusal turizm kongreleri bildirilerinin bibliyometrik profili, 14.Ulusal Turizm Kongresi Bildiri Kitabı, Kayseri: Erciyes Üniversitesi Turizm Fakültesi, 1429-1447

Çakır, M. (2017). Demokrasi Söylemi: Lisansüstü Tezler Üzerine Bir Araştırma, Mehmet Akif Ersoy Üniversitesi Sosyal Bilimler Dergisi, 9(22): 312-326.

Çiçek, D. ve Kozak, N. (2012). Anatolia: Turizm Araştırmaları Dergisi'nde yayımlanan hakem denetimli makalelerin bibliyometrik profili, Türk Kütüphaneciliği, 26(4): 734-756

Demirbulat, Ö. G. ve Dinç, N. T. (2017). Sürdürülebilir Turizm Konulu Lisansüstü Tezlerin Bibliyometrik Profili, Seyahat ve Otel İşletmeciliği Dergisi, 14(2): 20-30.

ENAT-European Network for Accessible Tourism (2012). The Underestimated Market Potential of Barrier-free Tourism, World Travel Monitor Forum, Pisa. [http://www.accessibletourism.org/resources/enat-the-underestimated-market.pdf]. Date of Access: 18.09.2019.

Evren, S. and Kozak, N. (2014). Bibliometric Analysis of Tourism and Hospitality Related Articles Published in Turkey, Anatolia, 25(1): 61-80.

Ey-Der (Engelsiz Yaşama Derneği). (2019). https://ey-der.com/ana-sayfa/turkiye-ve-dunyadaengelliler/ (Erişim: 22.10.2019).

Hall, C. M. (1991). Tourism as The Subject of Post-Graduate Dissertations in Australia, Annals of Tourism Research, 18: 520- 523.

ITB Berlin. (2012). World travel trends report 2012/2013. Retrieved from http://www.itbberlin.de/media/itbk/itbk_media/itbk_pdf/WTTR_Report_2013_web.pdf. Date of Access: 18.09.2019.

İnce, M., Gül, H. ve Bozyiğit, S. (2017). Türkiye'de Turizm Pazarlaması Konusunda Yazılan Lisansüstü Tezlerin İçerik Analizi Yöntemiyle İncelenmesi: 1990-2016, Manas Sosyal Araştırmalar Dergisi, 6(5): 113-129.

Jafari, J. and Aaser, D. (1988). Tourism as the Subject of Doctoral Dissertations, Annals of Tourism Research, 15: 407- 429.

Jamal, T., Smith, B. and Watson, E. (2008). Ranking, Rating and Scoring of Tourism Journals: Interdisciplinary Challenges and Innovations, Tourism Management, 29(1): 66-78.

Jogaratnam, G., Chon, K., McCleary, K., Mena, M. and Yoo, J. (2005). An Analysis of Institutional Contributors to Three Major Academic Tourism Journals: 1992-2001, Tourism Management, 26(5): 641-648.

Koç, E. and Boz, H. (2014). Triangulation in Tourism Research: A Bibliometric Study of Top Three Tourism Journals, Tourism Management Perspectives, 12: 9-14.

Kozak, N. (2001). Türkiye' de Turizm Pazarlaması Literatürünün Gelişim Süreci: 1972- 1998 Yılları Arasında Hazırlamış Lisansüstü Tez Çalışmaları Üzerine BiyoBibliyografik Bir İnceleme, Anatolia: Turizm Araştırmaları Dergisi, 12: 26-33.

Kozak, M. and Kozak, N. (2016). Institutionalisation of tourism research and education: from the early 1900s to 2000s, Journal of Tourism History, 8(3): 275-299. 
Köseoğlu, M. A., Sehitoglu, Y. and Parnell, J. A. (2015). A Bibliometric Analysis of Scholarly Work in Leading Tourism and Hospitality Journals: The Case of Turkey, Anatolia, 26(3): 359-371.

Köseoğlu, M. A., Sehitoglu, Y. and Craft, J. (2015). Academic Foundations of Hospitality Management Research with An Emerging Country Focus: A Citation and Co-Citation Analysis, International Journal of Hospitality Management, 45: 130-144.

Köseoğlu, M. A., Rahimi, R., Okumus, F. and Liu, J. (2016). Bibliometric Studies in Tourism, Annals of Tourism Research, 61: 180-198.

Köseoğlu, M. A., Sehitoglu, Y., Ross, G. and Parnell, J. A. (2016). The Evolution of Business Ethics Research in the Realm of Tourism and Hospitality: A Bibliometric Analysis, International Journal of Contemporary Hospitality Management, 28(8): 1598-1621.

Kushowski, J.D., Parsons, K.A. and Wiese, H. (2003). Master's and Doctoral Thesis Citations: Analysis and Trends of a Longitudinal Study, Libraries and the Academy, 3(3): 459-479.

Lee, S. H. (2015). A Bibliometric Analysis of the Field of Records Management: A Case Study of "Records Management Journal", 1989-2013 (Order No. 1598971), Available from ProQuest Dissertations \& Theses Global.

McKercher, B., Law, R. and Lam, T. (2006). Rating tourism and hospitality journals, Tourism Management, 27(6): 1235-1252.

McKercher, B. (2008). A citation analysis of tourism scholars, Tourism Management, 29: 1226-1232.

Meyer-Arendt, K. J. (2000). Commentary: Tourism Geography as the Subject of North American Doctoral Dissertations and Master's Theses, 1951-98, Tourism Geographies: An International Journal of Tourism Space, Place and Environment, 2: 140- 156.

Meyer-Arendt, K. J. and Justice, C. (2002). Tourism as the Subject of North American Doctoral Dissertations, 1987-2000. Annals of Tourism Research, 29: 1171- 1174.

Miller, P. M., Vandome A. F. and McBrewster, J. (Ed.) (2010). Bibliometrics. USA: Alphascript Publishing.

Nergis, G. (2014). Türkiye' de Lisansüstü Turizm Tezlerinin Bibliyometrik Profili (1990-2013). VII. Lisansüstü Turizm Öğrencileri Araştırma Kongresi, Kuşadası, Aydın (04-05 Nisan).

Nunkoo, R., Smith, S. L. and Ramkissoon, H. (2013). Residents' Attitudes to Tourism: A Longitudinal Study of 140 Articles From 1984 to 2010, Journal of Sustainable Tourism, 21(1): 5-25.

Okubo, Y. (1997). Bibliometric Indicators and Analysis of Research Dystems: Methods and Examples. STI Working Papers. Paris: OECD.

Okumuş, B., Köseoğlu, M.A. and Ma, F. (2018). Food and Gastronomy Research in Tourism and Hospitality: A Bibliometric Analysis, International Journal of Hospitality Management, 73: 64-74.

Oviedo-Garcia, M. A. (2016). Tourism Research Quality: Reviewing and Assessing Interdisciplinarity, Tourism Management, 52: 586-592.

Öcal, M. (2014). Ulusal ve Uluslararası Politikalar Çerçevesinde Engellilerin İstihdamını Artırmaya Yönelik Politikalar. Çalışma ve Sosyal Güvenlik Bakanlığı Türkiye İş Kurumu Genel Müdürlüğü Uzmanlık Tezi.

Özel, Ç. H. ve Kozak, N. (2012). Turizm pazarlaması alanının bibliyometrik profili (2000-2010) ve bir atıf analizi çalışması, Türk Kütüphaneciliği, 26(4): 715-733 
Palmer, A. L., Sesé, A. and Montano, J. J. (2005). Tourism and Statistics: Bibliometric Study 19982002, Annals of Tourism Research, 32(1): 167-178.

Richards V., Pritchard A., and Morgan N. (2010). (Re)envisioning Tourism and Visual Impairment, Annals of Tourism Research, 37(4): 1097-1116.

Pritchard, A. (1969). Statistical Bibliography or Bibliometrics? Journal of Documentation, 25: 348349.

Rogerson, C. M. and Rogerson, J. M. (2011). Tourism Research Within the Southern African Development Community: Production and Consumption in Academic Journals, 2000-2010, Tourism Review International, 15(1-2): 213-224.

Ruhanen, L., Weiler, B., Moyle, B. D. and McLennan, C. L. J. (2015). Trends and Patterns in Sustainable Tourism Research: A 25-year Bibliometric Analysis, Journal of Sustainable Tourism, 23(4): 517-535.

Sánchez, A. D., Del Río Rama, M. D. L. C. and García, J. Á. (2017). Bibliometric Analysis of Publications on Wine Tourism in the Databases Scopus and WoS, European Research on Management and Business Economics, 23(1): 8-15.

Sökmen, C. and Özkanlı, O. (2018). Gastronomi Turizmi Alanyazının Gelişimi: Journal of Tourism and Gastronomy Studies Dergisinde Yayımlanan Makaleler Üzerine Bir İnceleme, Journal of Tourism and Gastronomy Studies, 99: 127

Sünnetçioğlu, A., Yalçınkaya, P., Olcay, M. ve Mercan, Ş.O. (2017). Turizm Alanında Yazılmış Olan Gastronomiye İlişkin Tezlerin Bibliyometrik Profili, Journal of Tourism and Gastronomy Studies. 5(2): 345-354.

Şahin, S. ve Acun, A. (2015), Turist Rehberliği Alanının Bibliyometrik Profili (Makaleler ve Lisansüstü Tezler), 16. Ulusal Turizm Kongresi, Çanakkale Onsekiz Mart Üniversitesi, Çanakkale, 14561475.

Şakar, G. D. ve Cerit, A. G. (2013). Uluslararası Alan İndekslerinde Türkiye Pazarlama Yazını: Bibliyometrik Analizler ve Nitel Bir Araştırma, Atatürk Üniversitesi İktisadi ve İdari Bilimler Dergisi, 27(4)

Şencan, H. (2005). Sosyal ve Davranışsal Ölçümlerde Geçerlilik ve Güvenilirlik. Ankara: Seçkin Yayınevi.

Tayfun, A., Küçükergin, F.G., Aysen, E., Eren, A. ve Özekici, Y.K. (2016). Turizm Alanında Yazılan Lisansüstü Tezlere Yönelik Bibliyometrik Bir Analiz, Gazi Üniversitesi Turizm Fakültesi Dergisi, I: 50-69.

Tayfun, A., Ülker, M., Gökçe, Y., Tengilimoğlu, E., Sürücü, Ç. ve Durmaz, M. (2018). Turizm Alanında Yiyecek ve İçecek ile İlgili Lisansüstü Tezlerin Bibliyometrik Analizi, Journal of Tourism and Gastronomy Studies, 523-547.

Tekin, Ö. A. (2016). Türkiye'deki Lisansüstü Turizm Tezlerinde Odaklanılan Konular: 1984-2015, Journal of Alanya Faculty of Business/Alanya İşletme Fakültesi Dergisi, 8(2).

Temizkan, S. P., Çiçek, D. ve Özdemir, C. (2015). Sağlık Turizmi Konusunda Yayınlanan Makalelerin Bibliyometrik Profili, International Journal of Human Sciences, 12(2): 394-415.

Turan, A. (2014), Turizm Konulu Yüksek Lisans Tezlerinin Bibliyometrik Özellikleri (1984-2013), VII. Lisansüstü Turizm Öğrencileri Araştırma Kongresi, Kuşadası, Aydın (04-05 Nisan), 3-15. 
Türktarhan, G. (2014). Türkiye'de Turizm Alanyazınının İncelenmesi: Sistematik Türkiye Turizm İşletmeciliği Bibliyografyası (1929-1984) Üzerine Bir İnceleme. N. Kozak ve E. Günlü (Ed.), VII. Lisansüstü Turizm Öğrencileri Araştırma Kongresi bildiri kitabı içinde, 182-199. Ankara.

Üsdiken, B. ve Pasadeos, Y. (1992). Türkiye'de Yayımlanan Yönetimle İlgili Veri Temelli Makalelerde Yöntem, ODTÜ Gelişme Dergisi, 19(2): 249-266.

Üstüner, M. ve Cömert, M. (2008). Eğitim Yönetimi Teftişi Planlaması ve Ekonomisi Anabilim Dalı Lisansüstü Dersleri ve Tezlerine İlişkin Bir İnceleme, Kuram ve Uygulamada Eğitim Yönetimi, 55: 497-515.

Yıldırım, C. (2005). Bilim Felsefesi. Ankara: Remzi Yayınları.

Yıldırım, A. ve Şimşek, H. (2013). Sosyal bilimlerde nitel araştırma yöntemleri. (9. Baskı). Ankara: Seçkin Yayıncılık.

Yılmaz, G. (2017). Ulusal Turizm Kongrelerinde Gastronomi ve Mutfak Sanatları Alanı ile İlgili Yayınlanan Bildiriler Üzerine Bir Araştırma, Turizm ve Araştırma Dergisi, 6(1): 24-39.

Yonghee, K., Savage, K. S., Howey, R. M. and Van Hoof, H. B. (2009). Academic foundations for hospitality and tourism research: A reexamination of citations, Tourism Management, 30: 752- 758.

YÖK (Yükseköğretim Kurulu). (1981). Lisansüstü Ĕğitim ve Öğretim Yönetmeliği. http://www.yok.gov.tr/documents/10279/23688337/lisansustu_egitim_ve_ogretim_y\%C3\%B6net meligi.pdf/8451c3e1-7975-40f1-bc81-3ca01cb288c8, (Erişim: 02.01.2019).

YÖK (Yükseköğretim Kurulu). (2010). Yükseköğretim Kurumlarında Hazırlanan Lisansüstü Tezlerin Internet Üzerinden Derlenmesi Hakkında Kilavuz. https://tez.yok.gov.tr/UlusalTezMerkezi/tezTeslimKilavuz.jsp, (Erişim: 20.01.2019).

YÖK (Yükseköğretim Kurulu). (2019). https://tez.yok.gov.tr/UlusalTezMerkezi/istatistikler.jsp (Erişim: 20.10.2019).

Yüncü, D. K. ve Kozak, N. (2012). Anatolia Turizm Araştırmaları Dergisi'nin Bibliyometrik Analizi: Araştırma Konuları ve Kurumlar Arası İşbirliğinin Sosyal A ̆ Analiz ile İncelenmesi, VI. Lisansüstü Turizm Öğrencileri Araştırma Kongresi Bildiriler Kitabı içinde, 642-660.

Zencir, E. ve Kozak, N. (2012). Sosyal Bilimler Enstitüsü Enstitü Dergilerinde yayımlanan turizm makalelerinin bibliyometrik profili (2000-2010). N. Kozak ve M. Yeşiltaş (Yay. Haz.). VI. Lisansüstü turizm öğrencileri araştırma kongresi bildiri kitabı içinde, 673-685.

Zopiatis, A., Theocharous, A. L. and Constanti, P. (2015). The Past is Prologue to the Future: An Introspective View of Hospitality and Tourism Research, Scientometrics, 102(2): 1731-1753. 